\title{
Care, laboratory beagles and affective utopia
}

\begin{abstract}
:
A caring approach to knowledge production has been portrayed as epistemologically radical, ethically vital and as fostering continuous responsibility between researchers and researchsubjects. This article examines these arguments through focusing on the ambivalent role of care within the first large-scale experimental beagle colony, a self-professed 'beagle utopia' at the University of California, Davis, (1951-1986). We argue that care was at the core of the beagle colony; the lived environment was re-shaped in response to animals 'speaking back' to researchers, and 'love' and 'kindness' were important considerations during staff recruitment. Ultimately, however, we show that care-relations were used to manufacture compliancy, preventing the predetermined ends of the experiment from being troubled. Rather than suggesting Davis would have been less ethically troubling, or more epistemologically radical, with 'better' care, however, we suggest the case troubles existing care theory and argue that greater attention needs to be paid to histories, contexts, and exclusions.
\end{abstract}

Keywords: affect, care, animals, embodied communication, laboratory science, ethics, dogs 


\section{Care, laboratory beagles and affective utopia}

...our primary objective was to establish an ecologic balance or utopic

environment that would minimise the over-all effects of stresses and stressors.

(Andersen \& Goldman, 1960: 131).

This article complicates arguments that have been made about the ethical and epistemic importance of care; arguments which have gained currency in a range of (often overlapping) academic contexts, including cultural studies (Despret, 2013; Haraway, 2008; Latimer \& Miele, 2013), cultural geography (Greenhough, 2010; McEwan \& Goodman, 2010), and science and technology studies (Mol et al, 2010; Puig de la Bellacasa, 2011). To flesh out a more critical account of care we focus on the 'utopic environment' described above: The first large-scale experimental beagle colony that was developed and run at University of California Davis between 1951 and 1986. Funded by the Manhattan Project, this colony’s primary function was to test the long-term effects of radiation. However, it was also intended to be a model beagle colony where lessons - in architectural design, management and carepractices - could be learned for future initiatives. Researchers' arresting accounts of the colony as a beagle utopia, where affective human-animal encounters were not only allowed to flourish but actively shape the research environment, are - seemingly - illustrative of the conceptual and practical importance of care. Care was integral in learning about the animals' needs, needs which shaped the colony's own design and ethical procedures in a profound way and went on to shape future laboratory practice. Yet care at Davis was (in Donna Haraway’s terms) 'non-innocent' and used to facilitate practices that (in retrospect) seem questionable. The striking account of this beagle utopia, as detailed below, is only half of the story, however, as the messy role of care in the colony has broader theoretical resonance, complicating existing claims about the ethical and epistemological value of care. 
Eva Giraud and Gregory Hollin

Before examining care's role in this specific context, we explore some of the recent conceptualisations of care that - though constituting a heterogeneous body of work consistently emphasise its importance for crafting not only more ethical but more epistemologically radical forms of knowledge. These claims are then complicated through a sustained focus on Davis, which leads into our concluding discussion about what can be learned from interrogating some of the less 'innocent' qualities of care.

\section{The importance of care}

It has been argued that care not only does (Pickersgill, 2012) but should play an integral role in scientific knowledge production and medical work. If care is more comprehensively accommodated into technoscientific practice, it is claimed, then this is ethically valuable, enabling researchers to respond to the needs and demands of those being researched (Despret, 2004; Despret, 2013). It is also claimed that care has epistemological value, facilitating more responsive relationships between researchers and research-subjects and making it difficult to manipulate subjects into merely conforming with pre-established assumptions (Stengers, 1997; Stengers, 2010; Stengers, 2011). Care has thus been depicted as enabling researchsubjects to 'speak back' in some way and, in line with Isabelle Stengers, 'speaking back' is what distinguishes 'good' from 'bad' science. For Stengers, conversely, if what is studied is prevented from 'speaking back' scientific practice is undermined because 'the research has been done with the ulterior motive of imposing an answer on it' (McClintock in Stengers, 1997: 126).

There are, however, difficulties in facilitating an environment wherein research subjects may 'speak back', especially when the subjects under consideration are 'lively’; as Matei Candea argues: 'Animal and human objects, unlike atoms or cells, are more easily affected by “obligations” (rules and constraints imposed by experimenters) and may find it harder to 
Eva Giraud and Gregory Hollin

impose their own “requirements” on the scientist' (Candea, 2013: 57). It is difficult in such instances to create the space Stengers demands to 'ensure the object [of study] has been given every chance to "object” to the theories and assumptions of the scientist' (Candea, 2013: 108). In research with lively subjects, therefore, care is framed as being particularly important in overcoming the problem of obligation, because care-taking practices enable researchers to develop a more nuanced understanding of what research-subjects' needs are and respond to them accordingly (Davies, 2012; Greenhough, \& Roe 2011).

\section{Tinkering and affect}

Caring approaches are therefore understood as processes of relationship-formation which are attentive to the needs of others (Puig de la Bellacasa, 2011). Caring is fundamentally relational; a mode of engagement wherein responsibility is taken for our engagements and their effects on others (Stiegler, 2010). It is the relational nature of care, moreover, which obliges researchers to respond to the needs of those they work with, be they human patients (Silverman, 2012), primates (Haraway, 1991), rodents (Despret, 2004; Davies, 2012; Davies, 2013), cells (Stengers, 2010; Stengers, 2011) or even atoms (Barad, 2007). ${ }^{1}$

What this care 'looks like’, however, cannot be reduced to a universal set of principles (Puig de la Bellacasa, 2011). Care, instead, is said to emerge through mundane working practices that are particular to the settings it unfolds within, settings shown to include research laboratories (Despret, 2004); care-homes (Moser, 2010); hospitals (Mol, 2008) and farms (Harbers, 2010; Singleton, 2010). These context-specific care practices often elude formal ethical guidelines and procedures, either because they are tacit in nature (Holmberg, 2008) or because they evolve from somatic relations (Greenhough \& Roe, 2011). Instead of reliance upon guidelines, therefore, realizing care in practice involves 'tinkering' with existing sociotechnical infrastructures. Such 'tinkering' is required both to respond to the needs of those 
Eva Giraud and Gregory Hollin

being worked with and because negotiations need to take place concerning 'how different goals [...] might coexist in a given, specific, local practice’ (Mol et al, 2010: 13).

Importantly, though care might ultimately serve to support socio-economic systems, even in the most instrumental contexts care cannot be reduced to economic imperatives or be wholly contained by systemic parameters (Harbers, 2010).

An overlapping body of work stresses the affective dimension of caring practices, framing care as an 'affective state' (Puig de la Bellacasa, 2011: 89) with a vital role in 're-affecting objectified worlds' (98). Affect - in contrast to relational understandings of care - is taken to be a quality of actors that designates their capacity to affect others and be affected in turn (Lee, 2008: 66). ${ }^{2}$ Care and affect are, therefore, tightly bound. The value of care lies in its capacity to combat instrumentalization through creating the space to affect and be affected. Affect, meanwhile, strengthens care work because the affective relations between research partners create further space to learn what animals are articulating through their behaviour (Dror, 1999; Holmberg, 2008; Davies, 2012). Vinciane Despret describes this as an 'affected perspective' where 'the scientist risks being touched/affected by what matters for the animal he/she observes’ (Despret, 2013: 57). It is through such relations that animals can be enabled to 'speak back' in ways that reshape their environment.

\section{Problems with care}

Work that stresses the importance of care, however, has also pointed to the difficulties of realizing it in practice, with care depicted as frequently lying in tension with an everincreasing desire to regulate care-practices. Regulation could be for the purpose of control (as with systems in place to regulate cattle movement (Singleton, 2010)), to make practices easy to standardize (as with care-guidelines for laboratory mice (Davies, 2012)), for economic reasons (as with procedures prescribed in the wake of the 2001 foot and mouth crisis (Law, 
Eva Giraud and Gregory Hollin

2010)), or for all three. For Mol et al, the tensions between regulation and the tacit nature of care mean that if the former wins out then this: 'threatens to take the heart of out care - and along with this not just its kindness but also its effectiveness its tenacity and its strength' (Mol et al, 2010: 7). The affective qualities of care, therefore, are often depicted as being in tension with 'economic and organizational' requirements and 'commitments to scientific epistemologies’ that side-line the importance of care (Davies, 2012: 629).

Further, warnings have been made about valorising embodied relations (Latimer, 2013: 98) and of care itself becoming an 'epistemological standard' required for making 'better knowledge’ (Puig de la Bellacasa, 2011). Haraway (2008) and Despret’s (2013), respective, emphasis on care’s 'non-innocent' qualities even implicate it in processes that might have a detrimental effect on research partners, processes which include killing. Despite these issues, care is described as providing a way of 'staying with the trouble'; a refusal to settle ethical or epistemological matters by delegating them to rules, guidelines and values that are decided in advance (Haraway, 2011). Indeed, care has explicitly been opposed to 'other traditions of ethics and especially to the ethics of justice' that predetermines what is 'good' or 'bad' care (Mol et al, 2010), because such approaches shut down potential for continuous responsibility between researchers and research subjects.

What is revealed through focusing on Davis, however, is that these arguments need to be complicated further, taking into account what happens when care itself forecloses certain forms of responsibility. The role of care at Davis, we argue, cannot be accounted for by claiming that, while all relations are non-innocent, care’s emergence - in often adverse conditions - still holds potential for an ethics (Despret, 2013; Haraway, 2008). Nor can these problems be overcome by recognising the different values in play in care contexts and identifying tensions between the multiple forms of care that could exist in particular sites (e.g. Law, 2010). The laboratory beagles we focus on demonstrate that care is not always in 
Eva Giraud and Gregory Hollin

negotiation with or opposed to instrumental forces. In certain contexts care is precisely what enables the instrumentalization of life, in being used to gain knowledge about entities that can be exploited for the purpose of control.

At Davis caring relations did exist between researchers and beagles; for example, there was a good deal of 'tinkering' with ways in which to maximise animals' well-being within the constraints of the experimental context and affective encounters were not only accommodated but encouraged. These processes, though, did not ultimately expand the animals' opportunities to 'object', but were designed to control them more efficiently, to mould the animals into 'experimental dogs'. Indeed the beagles at Davis muddy distinctions between care and systemic imperatives. The affective encounters taking place within the colony actively enabled the laboratory’s systems to maintain and reproduce themselves. Researchers gained knowledge about the animals through caring practices and, in turn, this knowledge was then acted on and re-shaped caring practices in order to undermine the dogs' need to 'object' in disruptive ways. Despite these problems, care was still afforded a pivotal role and thus the work at Davis cannot simply be read in terms of a straight-forward narrative of instrumentalization, or even framed in relation to more complex socio-economic concepts that examine the animals’ role as biocapital (e.g. Shukin, 2009; Twine, 2010). Rather than labelling engagements with beagles 'uncaring' on a post hoc basis, we argue that a more critical theory of care itself is needed. The colony's conceptual significance, therefore, lies not in its capacity to deepen understanding of the laboratory per se but in the challenge it poses to theoretical accounts of care, both in the laboratory and - crucially - elsewhere, which contend that care is what opens space for nonanthropocentric forms of ethics and epistemological transformation. At stake in examining the ambivalent role of care in this context, in other words, is maintaining space to ask wider questions about 'for whom, for what and by whom' research takes place (Haraway, 2008: 87), in order to guard against care 
Eva Giraud and Gregory Hollin

being used to reinforce pre-existing (experimental) research epistemologies and ethical values rather than transforming them.

\section{Background and materials}

In order to elucidate the role of care within beagle-research, we focus upon work which took place at The Radiobiology Laboratory at Davis. In addition to the colony still being cited in the literature as a touchstone for research (Tomkins et al, 2011), in methodological terms our focus on this particular case study takes a lead from previous work that has drawn on privileged historical sites of experimental research to tease out the tensions and potentials of contemporary laboratory work (e.g. Haraway, 1991, 1997; Despret, 2004, 2013). This approach also complements ethnographic analyses of human-animal relations, by responding to recent calls to move beyond immediate laboratory encounters and expand on the histories that form the context of this research (Johnson, 2015).

Our analysis of the research at Davis was largely possible because the experimenters firmly believed themselves to be at the forefront of animal experimentation. Between them, the academics at Davis published a great deal of research concerned not with radiobiology but, rather, the establishment and maintenance of a large, experimental, 'model' beagle colony intended to shape all the other similar projects which would surely follow in its wake. Thus, a critical reading of a range of printed sources originating from within the laboratory Annual Progress Reports, conference proceedings, journal articles, and a 600 page textbook entitled The Beagle as an Experimental Dog (Andersen, 1970) - form the core of our analysis. These primary, historical, documents are supplemented by a range of sources emerging after the conclusion of the experiments. These pieces include a Governmental report concerning the environmental impact of the study, newspaper articles, online sources, and preexisting interviews conducted with researchers. 
Eva Giraud and Gregory Hollin

Two intimately related projects took place at The Radiobiology Laboratory at Davis; the first, 'Project Four', commenced in 1951 with the ambition of studying the long-term effects of sub-lethal and mid-lethal x-irradiation exposure (Andersen \& Hart, 1955: 366). The second, 'Project Six', commenced in 1957 and examined the consequences of continuous low level ingestion of radionuclides (McKelvie \& Andersen, 1966: 25). These projects were funded by The Atomic Energy Commission, known prior to 1954 as The Manhattan Project. Further, the work at Davis was part of a larger network of similarly funded research centres, situated across the United States, attempting to gain insights into the effects of radiation exposure through the use of beagles as animal models (McKelvie et al, 1971: 264). This network, contemporary sources have suggested, was known as ‘the Beagle Club’ (Paddock, 1994: A1). Outside of the Beagle Club, independent research intent on consolidating the beagle as the laboratory breed of choice was also taking place in both the United States (e.g. Reinert \& Smith, 1963) and the United Kingdom (e.g. Appleton \& Appleton, 1967).

While we will engage in a fuller examination of the material features of the experimental environment at Davis, it is worth briefly noting the basic architecture of the site in order to give a sense of the project in question.

[Figure 1 to come here - picture of colony]

The project was big both geographically (the site ultimately occupied 15 acres of land (Dames \& Moore, 1995: 8)) and financially (costing approximately \$16 million (Wagner, 2011)). There was space to hold approximately 200 dogs in indoor kennels and it was standard practice for puppies to be weaned in these cages until the age of 19 months (Andersen, 1964: 296). Once weaned, dogs were moved outside; both Projects Four and Six had the capacity to hold between four and five hundred dogs within two-dog pens (Andersen \& Goldman, 1960: 129). In total, 1063 female beagles were exposed to radiation (Dames \& 
Eva Giraud and Gregory Hollin

Moore, 1995: 60) although, when we consider the initial breeding colony of 80 bitches and 7 dogs, female control subjects and male dogs that were utilized elsewhere or sold into the community, it becomes clear the total number of animals to have passed through the doors of the facility must have been far greater. The site finally closed in 1986, when the final beagle died, although concerns over radiation exposure and attempts to safely dispose of 1000 beagle corpses and 35 years' worth of radioactive faeces ensure that the experiment's halflife is of a long duration.

Following an examination of the research at Davis, we contest that the beagle experiments are infused, from beginning to end, with care; care that both facilitated and was shaped by the type of 'affected perspective' described by Despret. Affective encounters directed from beagle to beagle, from beagle to human, from human to beagle, and from human to human were enabled, and informed the experimental design, process, and the material experimental space itself. Ample space was provided for the 'objects to object' in a wide variety of ways and the material reality of experiment was demonstrably altered and shaped by these objections. Nonetheless, we contest that although, and indeed because, this infusion of affect forms the foundation for 'better care', affect is constructed as an instrument of the researcher, something mundane that is considered alongside economic and technical matters during experimental design. Though this could be seen as a form of 'tinkering', and demonstrably created certain ethical obligations for researchers, therefore, care was ultimately utilized to meet predetermined experimental goals.

\section{Affecting the design}

Why beagles?

The increasing use of beagles in the years following the Second World War appears to have been a response to increasing discontent with the use of 'random source' or 'normal' dogs 
Eva Giraud and Gregory Hollin

(Zinn, 1968: 1883). ${ }^{3}$ Arguments in favour of a move away from normal dogs had both ethical and epistemic components and were laden with considerations of affect (e.g. Burch, 1959: 805-806). The beagle itself quickly became established as the standardised laboratory dog for it had a vast number of characteristics it had in its favour. As researchers at Davis note:

The most desirable qualities of the Beagle as an experimental dog are its medium size, moderate length of hair coat in two or more colors, even temperament, adaptability to living in groups, representative conformation of the dog, and the lack of need for cosmetic surgery. The Beagle's excellent disposition and gay personality are two its greatest assets, because special handling is seldom necessary and a minimum amount of restraint is required for most experimental procedures. Its excellent disposition is the result of culling ill-tempered dogs throughout the history of the breed. Although a wide range of behavior traits can be identified in the Beagle, they rarely show aggressiveness, timidity, or shyness. (Andersen, 1970: 4)

In this extract it can be seen quite clearly that the beagle's affective qualities, for instance its ‘excellent disposition’ and 'gay personality’, are among its 'greatest assets' and have been taken into explicit consideration by the researchers at Davis, alongside other mundane qualities like size and hair length, when determining it to be the experimental breed of choice. It is worth stressing that this above quotation is not a one-off; the same desirable characteristics of the beagle are stressed repeatedly by researchers both at Davis (e.g. Andersen \& Goldman, 1960: 129; Solarz, 1970: 453) and elsewhere (Reinert \& Smith, 1963: 73; Scott 1970: 723; Zinn 1968: 1885). Indeed, the division between affect and economy is muddied here; because 'special handling' is rarely needed with the beagle and because they do not need to be 'restrained' (and pictures of the veterinarians at work at Davis (e.g., (McKelvie \& Andersen, 1966: 32) show, perhaps performatively, examinations being 
Eva Giraud and Gregory Hollin

conducted without as much as a leash) the beagle’s gay personality actually makes the experiment cheaper to run and makes the already-articulated goals of the experiment easier to achieve.

What is also significant about these experiments is that affect, and the care-giving practices it feeds into, does not simply exist on a tacit level. What is seen in beagle research is decisively not the process of 'forgetting' described by Gail Davies in relation to animal research more broadly, wherein: 'The extended scientific community has repeatedly been able to forget, or strategically ignore, the ways in which the affective states and environmental situations of animals may contribute to experimental outcomes’ (Davies, 2012: 629). In contrast with this account, affect here is documented, seen as integral to 'good science' by researchers themselves and, as will be discussed in the following section, acts as a model for future practice.

\section{Moulding a model colony: Affect in practice}

\section{Designing utopia}

As mentioned previously, the researchers at Davis saw the Radiobiology Laboratory as a model colony; the beagle was only just becoming the standardised dog for laboratory practice and lessons would be learnt at Davis which could be passed down to future researchers. What becomes apparent is that care is absolutely central to the project - the importance of the 'well-being' of the dogs is repeatedly stressed (Andersen, 1964: 300; Andersen \& Goldman, 1960: 135; Andersen \& Hart, 1955: 366; McKelvie \& Andersen, 1966: 25) and treating the dogs in a 'humane' manner (Andersen, 1955: 410) is understood to be both ethically and epistemologically important. Indeed, the 'tranquillity of experimental animals throughout a life span’ (Andersen \& Hart, 1955: 370) is stated to be crucial. It is even stated that 'our primary objective was to establish an ecologic balance or utopic environment that 
Eva Giraud and Gregory Hollin

would minimise the over-all effects of stresses and stressors' (Andersen \& Goldman, 1960: 131).

Here, we argue that the path of predetermined experimental progress was lubricated via a successful manipulation of the experimental space; a manipulation which exploited not only the affective qualities of the beagle but also the caring-relations between the beagles and the caretakers and laboratory technicians who were employed to work with them. Researchsubjects (both caretakers and beagles) were moulded into 'model' objects and their objections and desires pacified so that they could not threaten experimental goals. Any actor who could not be sufficiently moulded to the experiment was removed from the site. It is, however, difficult to dismiss these practices as simply 'uncaring' because these experiments display the attributes that are integral to existing theories of care (as illustrated by the pivotal role of affect and constant 'tinkering' in response to the animals' needs). To label the practices as Davis ‘bad care’ would thus necessitate an external position of judgement, a position rendered impossible by existing care-theories in their refusal to universalize or appeal to totalizing principles of social justice (Haraway, 1997; Haraway, 2008; Haraway, 2011; Mol et al, 2010). We suggest, therefore, that care theories need to take these tensions further into account, and guard against care being utilized for instrumental ends that inhibit ethical and epistemological change.

\section{Manipulating Affect}

What we seek to show here is that accommodating care does not necessarily create a more ethically responsive and epistemologically open laboratory; care at Davis was not just permitted but actively encouraged, documented and celebrated, yet it ultimately served as a mechanism of control. This intent is made explicitly clear in the following extract: 
...the Beagle has an excellent disposition which can be effected depending upon kennel management and environment. For example, Beagle pups raised in isolation become wild or skitish, an undesirable trait in any experimental animal. In our kennel, 2 or 3 litters of weaned pups were placed in a large pen adjacent to a well-traveled road to allow human contact. This resulted in Beagles which later welcomed handling by kennel personnel. The handling of pups early in life to reduce the 'critical distance' illustrates one of the many facets entering into successful operation of a Beagle kennel. Even though the qualities of the Beagle as an experimental dog are excellent, they can be greatly improved by the researcher having kindness, interest, and practical experience in the handling of this breed. (Andersen, 1970: 7)

It is clear from this extract that the researchers at Davis believe that systematically manipulating the affective responses of beagles by 'allowing human contact' and 'having kindness' is of great epistemic importance and will smooth the experimental progress. Resonating with Candea's argument that animals 'may find it harder to impose their own 'requirements' on the scientist' (Candea, 2013: 57), these practices seemingly give animals space to 'speak back' whilst actually minimizing the risk of future 'objections' troubling the predetermined ends of the experiment. In the following section we detail the ways in which this manipulation of affect, via care-taking processes, occurred in practice. We show that caring practices shape the physical design of the pens, the daily procedures, the agents (human and canine) given access to the experimental space, and the form of interactions between those agents (both intra- and inter-species).

\section{Care and the physical environment}


Eva Giraud and Gregory Hollin

The pens at Davis were approximately 13ft by $29 \mathrm{ft}$ (Andersen \& Hart, 1955: 367) and each contained two dogs. The floor was covered in crushed rock and from the centre of each pen rose a stanchion and platform, under which were attached two beer or wine kegs in which the beagles could sleep and shelter. These pens were arranged in two-wide-by-twelve-deep rows with an adjacent pen down one side and a walkway down from which personnel could gain access to the animals down the other. Animals were fed once daily and had access to an automatic watering device (see figure 1). The researchers claim that 'companionship, exercise, control of parasites, ease of cleaning, and minimum cost contributed to final decisions on design of the pens’ (McKelvie \& Andersen, 1966: 25).

It is clear that an affected perspective drastically shaped this eventual layout. Firstly, the size and shape of the pens was determined by the social needs of the dogs, with other options discarded when the beagles appeared to show discontent:

The wandering tendency [of beagles] can be minimized with pens of adequate size arranged for companionship and social activity. Previous studies gave evidence that rectangular pens (1 pen: 2 dogs) providing at least 10 sq. ft. per inch of body height are satisfactory when dogs are kept in pairs. Pens of other shapes and sizes resulted in uneven surface coverage by the dogs and encouraged digging or fence jumping. (Andersen \& Goldman, 1960: 129-130)

'Pacing', or 'uneven surface coverage', ‘digging' and 'fencing jumping' are the forms of 'objection’ most frequently described by the researchers and, as evidenced in the above quote, modifications took place in order to quell such behaviours. Affective encounters were thus used to gain knowledge about what mattered to the dogs, which then shaped their living environment; this process, however, served to ameliorate the risk of animals’ future objections disrupting the experiment. 
Eva Giraud and Gregory Hollin

Similarly, the number of dogs to a pen, and the positioning of the pens in relation to each other, is described as meeting the dogs' approval, letting each animal's own 'personality' flourish. Once again, the animals’ objections - pacing, jumping, digging - have been taken into account and the space altered in order to increase 'contentment':

Frequent, and often serious, quarrels develop if more than 2 dogs are kept together. A single dog within a large pen either becomes lethargic or develops some undesirable traits such as pacing, digging, or jumping... A social relationship between paired dogs adds to their contentment. Four adjacent pens separated by fencing permits muzzle contact between 8 dogs. We have confirmed that a social relationship does exist within a given group, with introverts and extroverts exhibiting characteristic moods. For example, females in estrus commonly prefer isolation to a group meeting at the corner of their pens. Thus the adjacent arrangements of pens favors a voluntary social relationship without jeopardizing the dogs’ well being... (Andersen \& Goldman, 1960: 134)

This process is seemingly illustrative of the 'tinkering' necessary to realise care within contexts shaped by technoscientific imperatives. The authors' take pains to demonstrate that a great deal of trial, error, and accommodation has gone into the pen design at Davis and that other researchers would be wise to follow their designs. The beagles are described as being content within their environment. After listening to the animals' desires, the beagles no longer object to their confinement:

This arrangement [of the pens] adds to contentment of the experimental animals and makes restraining barbed wire above the fence unnecessary. Approximately 400 dogs have been raised and kept within a 5-ft. fence and none has jumped the 
Eva Giraud and Gregory Hollin

enclosure. Animals removed from their permanent quarters appear lost and show a desire to return to their respective pens. (Andersen \& Hart, 1955: 371)

What we want to stress, in the light of these considerations, is that the researchers were not merely accommodating the affective qualities of the beagles. Rather, as shown in the previous section, they were learning from them in order to actively manipulate these qualities, moulding the animals into 'experimental dogs': the researcher 'having kindness' greatly improves the qualities of the beagle within a laboratory setting. Care is an instrument of both ethical and epistemic import and certainly creates space for affect, but, in this instance, knowledge is not transformed under the influence of care, as existing theories might anticipate. Instead care is used to transform research-subjects. The researchers use and acquire knowledge about care in order to mould the beagles and ensure their compliance, with affect serving as a powerful tool in this acquisition of knowledge. On one level Davis thus illustrates the forms of human-animal engagement advocated by theories which have highlighted the 'non-innocent' function of care and acknowledged that the purpose of minimizing animal stress is often to manage animals more easily (Haraway, 2008: 83; Despret, 2013: 70). One another level, however, it troubles these theories’ epistemological and ethical claims, specifically the assertion that - despite its sometimes 'non-innocent' role - care nonetheless fosters responsibility that even extends to bringing 'the enterprise to a halt' if necessary (Haraway, 2008: 82). When focusing on the inter-agential relations at Davis, for instance, care can be seen as reinforcing experimental norms, rather than creating possibilities to transform them.

\section{Care and the inter-agent environment}

At Davis, the affective responses of the beagle were not only controlled through a manipulation of the physical environment but also through an active policing of the agents - 
Eva Giraud and Gregory Hollin

both human and canine - that particular individuals came into contact with, for how long, and under what circumstances. Once again, these manipulations were intended to make experimentation on the beagles easier to conduct and care-taking practices played a pivotal role.

One particular area of concern was the amount of contact that beagles had with humans for, as mentioned previously, contact between humans and beagles made the animals easier to handle within the laboratory. For example, a previously referenced paper states that '2 or 3 litters of weaned pups were placed in a large pen adjacent to a well-traveled road to allow human contact. This resulted in Beagles which later welcomed handling by kennel personnel' (Andersen, 1970: 7). The researchers took other steps, in areas over which they had a great deal more control than the amount of passing traffic, to ensure frequent contact between beagles and humans.

The pathways down one side of each kennel allowed frequent human-beagle contact and it was believed to be desirable for humans to enter the pens on a frequent basis. The search for an economically viable means of ensuring frequent contact, in order to facilitate experimental ends, resulted in the use of crushed rock as a floor surface in the pens; a decision made, partially, because it forced contact between caretakers and dogs. As is repeatedly (Andersen \& Goldman, 1960: 130; Andersen \& Hart, 1955: 370) noted:

The use of a crushed rock pen surface means that fecal material must be manually removed to keep the pens clean. Manual removal of fecal material necessitates a daily human-animal association, which is an asset in handling the Beagles for experimental procedures. It has been determined that caretakers are inside a dog pen about 1 1/2 minutes a day. (Andersen, 1970: 14) 
Eva Giraud and Gregory Hollin

As the researchers were aware that, for beagles, as little as 8 minutes contact time per week was required to socialise the dogs (Solarz, 1970: 462) and minimise the 'critical distance', the choice of this surfacing was both economically viable and affectively productive, combining what are repeatedly articulated as the two variables of foremost consideration when designing the experiment. Indeed, it was even recommended that the experiment would progress more smoothly if laboratory personnel were likely to form caring relationships with the animals. When making appointments, 'personality traits which could influence animal behaviour are of primary concern’ (McKelvie \& Solarz, 1966: 115) and caretakers with a 'great love for animals' were highly valued by the experimenters. Indeed, a scale assessing 'attitude towards animals' was included on a short questionnaire which, it was recommended, other laboratories might use during recruitment in order to avoid 'personnel problems' in their colony (McKelvie \& Solarz, 1966: 112). It is also worth noting that employees who could not form caring relations with other humans, those who were 'not in accord with fellow workers’ (McKelvie \& Solarz, 1966: 110) were deemed to be similarly problematic.

As has been shown above, a great deal of care was taken by the researchers to ensure that the experimental space took account of dogs’ affective needs and manipulated those affective qualities, for experimental ends, by controlling the frequency and form of interactions which animals experienced; this was the case both within and between species. Increasingly, the researchers even began to collapse the species divide when it came to manipulating affective responses. A number of years into the work at the Radiobiology Laboratory a psychologist, Andrew Solarz, began to work at the colony and, with spotting glasses in hand, Solarz engaged in long periods of observation from the top of a purpose built tower (Solarz, 1964: 928). One of the first papers which Solarz published concerned the impact of beagle-beagle relations upon human-beagle relations (Solarz, 1965). What Solarz concluded was that dogs in the most utopic environments, those in 'parallel possession' of their pen where 'interaction 
Eva Giraud and Gregory Hollin

was non-combative and neither dog showed...dominance - both dogs shared the cache [food] without observable friction' (Solarz, 1965: 1254), were more likely to show 'friendly' behaviour towards caretakers, moving towards the humans and wagging their tails when they entered the dogs’ pen (Solarz, 1965: 1256), thus making them more amenable to experimental study. Furthermore, because social behaviours could be learnt from both humans and beagles (Solarz, 1965: 1256), and because dominance hierarchies were reported to be more likely to occur when there was a significant disparity in the body-weight of a pen’s two dogs, beagle-beagle-human affect was a variable open to control (McKelvie et al, 1971: 274). Behavioural experiments such as these were only introduced nine years into the study (Solarz, 1964: 928) and because it had already been determined that pairs would be matched for life (Solarz, 1965: 1254) pairs were not altered in an attempt to effect affect. Nonetheless, this was a model colony, lessons were to be learned and taken forward, and the researchers explicitly recommended that others base their pairings with these findings in mind (McKelvie et al, 1971: 274). A utopic environment, both physical and social, was to be positively strived for.

The construction of this 'beagle utopia' illustrates how processes of affective trans-species communication (Despret, 2004), can not only accommodated but actively encouraged in animal research. At Davis care-taking practices were shaped by affect and documented, so as not to 'forget' these insights (as Davies suggests is commonly the case (2012)). It is problematic to frame the forms of care at Davis as opening space for new forms of ethics, however, let alone new research epistemologies, as these practices ultimately served to manufacture compliant animals, reinforced the experimental status quo and had consequences for both dogs and care-takers who resisted entering into affective-encounters.

When care fails 
Eva Giraud and Gregory Hollin

What we have detailed above is a complex process of accommodation and manipulation in relation to care which was carried out with the intent of furthering experimental ends. It needs to be noted, however, that there were instances wherein care and affective requirements could not be made to cohere to the demands of the experiment. In these instances, the responses of the researchers were quite different. Firstly, it has already been noted that the beagle’s 'excellent disposition is the result of culling ill-tempered dogs throughout the history of the breed' (Andersen, 1970: 4) and this act was repeated within Davis. Out of the animals initially bought to form the breeding colony, ' 15 females and 1 male were culled because of undesirable characteristics’ (Andersen \& Hart, 1955: 366). Similarly, those employees who neither cared for the animals nor their fellow workers were not hired or, on more than one occasion, relieved of their duties (McKelvie \& Solarz, 1966: 110).

Individuals unsuitable for the experimental environment were not only those who showed a lack of care, as detailed above; caretakers who showed too much care were deemed similarly problematic. For example, it is noted that 'one employee gave certain dogs pet names' (McKelvie \& Solarz, 1966: 111). There is no suggestion within the literature that this employee neglected the other animals and yet this lack of standardised treatment was deemed unacceptable for the experiment and was apparently stamped out. Further, animals which attracted too much care were reportedly troublesome. The researchers note:

...one animal, considerably smaller than the others, was maintained until its death, at over ten years of age. When autopsy was scheduled, none of the caretakers wanted to assist. The implication is obvious. What effect the constant attention of the caretakers may have had had is purely speculative, but was undoubtedly real. (McKelvie \& Solarz, 1966: 111) 
The recommendation is that future studies standardise their research subjects to prevent such an occurrence of 'constant attention'. Much as the beagles objected to the experiment with uneven coverage of their pens, the researchers found uneven courage of caregiving objectionable; the only manner in which these objections could be accommodated was through the removal of certain individuals, beagle or human, from the experimental space.

A final affective quality that could not be made to cohere to the experimental regime is the beagles' 'loud penetrating bark, which can be heard from a great distance... almost any excuse will incite an entire colony to bark' (Andersen, 1970: 6). This bark is variously described as ‘objectionable’ (Andersen \& Hart, 1955: 366) and 'annoying’ (Andersen, 1955: 409) and appears to have been problematic for both those working at the facility and local residents (Andersen, 1955: 410). Unlike digging, pacing, or jumping the bark of the beagle could not be controlled and, as a result, each animal at the Radiobiology Laboratory was 'debarked' at the age three through a surgical procedure known as a ventriculocordectomy which, while not entirely eliminating the ability to bark, significantly reduced its volume (Andersen, 1955).

We do not want to dismiss these seemingly uncaring practices, far from it. However we are reluctant to suggest that these practices which are, after all, similarly aimed at manipulating affect within the confines of the experiment, should be understood separately to the instances of care detailed above. Neither do we believe that the researchers' claims of 'kindness' should be dismissed, post hoc, from an external position of judgement or in light of contemporary understandings of these practices as problematic. We need a theory of care which can simultaneously recognize that kindness and debarking are a product of the same affective perspectives, and which understands care as not only being open to manipulation but actively supporting instrumentalization. 
Eva Giraud and Gregory Hollin

\section{Conclusion}

Within the existing literature, care has been seen as important for experimental research due to its capacity to support relations between researchers and research-subjects; relations which not only foster continuous ethical responsibility but engender new forms of knowledge. Care, firstly, has been framed as something mundane and tacit; an inevitable part of scientific research which nonetheless requires constant negotiation and tinkering in order to be accommodated by the systems it lies in uneasy relation with. The affective qualities of care, too, have been stressed; whilst good care does not assume a prescriptive form, it nonetheless relies on researchers being open to affective encounters. These interrelated arguments understand care as vital in creating space for research partners to speak back in ethically and epistemologically significant ways.

At stake in care-relations, therefore, is making research open to the risk of new knowledge being produced, or existing ethical values being challenged. 'Good science' that holds potential for epistemological transformation, for instance, is repeatedly framed as being predicated on the 'risk' of being affected (Despret, 2013: 57; Haraway, 2008: 83; Latour, 1997: xix; Stengers, 1997: 18). Risk, too, is central to practices of 'tinkering' as 'care seeks to lighten what is heavy, and even if it fails it keeps on trying' (Mol et al, 2010: 14). Care should ensure that tensions between the different requirements of those engaged in research, and the risks involved, cannot be permanently resolved through drawing on predetermined values such as 'inviolable animal rights' or 'human good is more important' (Haraway, 2008: 87). Davis, however, troubles these claims.

The beagle colony at Davis had, at its core, practices of tinkering (as researchers experimented with different ways of creating the 'most utopic' environment for the dogs) and affect (with ordinarily tacit qualities such as 'love' and 'kindness' determining staff selection, 
Eva Giraud and Gregory Hollin

cage arrangements, care-taking routines and even pen surfacing). These approaches not only encouraged but necessitated the animals 'speaking back' and thus seemingly opened the potential for ethical responsibility and epistemological change. Ultimately, however, care was used to mould the dogs' capacity to impose obligations on researchers. The beagle became an 'experimental dog' whose objections and desires were pacified so that they could not threaten experimental goals and, ultimately, their behaviour strengthened - rather than troubled - the pre-determined ends of the experiment.

Further, care was used to reveal qualities (or even specific agents) that resisted being-inrelation and eliminate them. Dogs refusing care were labelled 'bad tempered' (and culled), conversely, care-takers had to demonstrate love to be employable. Such findings suggest that the power dynamics of risk matter in significant ways. In the beagle colony the risk for researchers, for instance, was that their research did not go as planned, but lessons could still be learned for future colonies (as when they learned about the importance of paired animals' weight). The risk for the animals, however, was fatal, as beagles died in the months when these adjustments were on-going. Similarly, when care-takers took the risk of being affected this was seen as a problem and even led to individuals losing their jobs. The point of highlighting these tensions at Davis, however, is not to suggest that they are anomalies that can be resolved through 'more care' or 'better care'. Instead we propose that the beagles of Davis demonstrate a need to complicate existing characterisations of care.

To move towards this more complex account of care, building on concerns that have been articulated within existing care-theories, we argue that further attention should be paid to the histories (Greenhough \& Roe, 2011), contexts (Johnson, 2015) and exclusions (Puig de la Bellacasa, 2011) that lie behind caring encounters (from the shaping of particular breeds, to the instrumentalization of affect within the laboratory). This approach, however, needs to be coupled with careful consideration of the role of care itself in manufacturing compliance, in 
order to ensure that a lack of obvious 'objection' is not equated with consent. While care can highlight exclusions (Puig de la Bellacasa, 2011) it can also foster them and, in order to guard against this, researchers' ethical obligations should move beyond immediate somatic relations, to take into account the disparate agents who were shaped or even excluded in the process of facilitating productive relations of care. Drawing attention to exclusions, histories and the ambivalent role of care is, we maintain, important in 'staying with the trouble' by crafting more complex notions of ethical responsibility that maintain space for epistemological change.

\section{Acknowledgements}

We would like to thank Tracey Potts, for reading a previous draft of this article. We would also like to thank everyone who engaged with the paper when we presented earlier forms of it at the 'More-than-Human Bodily Entanglements' panel at the RGS/IBG annual conference in London (2014) and at EASST in Torun (2014). Greg Hollin is grateful for the support of the Foundation for the Sociology of Health and Illness. We would also like to thank the five anonymous reviewers for their supportive and constructive feedback.

\section{Notes}

${ }^{1}$ Though Heideggerian understandings of being as being intertwined with care have been pivotal to critical analyses of human exceptionalism, the theoretical approaches that are drawn on here have displayed wariness of this framework (see Haraway, 2008: 334, 368; Johnson, 2015: 301). For a re-working of Heidegger in relation to animal studies, see Acampora, 2006: 6-14.

${ }^{2}$ This is not to infer that 'affect' has been treated as an unproblematic 'good'. Lauren Berlant, for instance, highlights the manipulative role that affect can play in maintaining certain social inequalities. While Berlant's emphasis on affective environments frames affect in a slightly different way to the body of work drawn on here her work could provide a useful avenue for future work.

${ }^{3}$ The beagle colonies at Davis were in line with a long lineage of research that took animal affect into account alongside scientific and economic imperatives: Beginning with experimental physiology in the late $19^{\text {th }}$ century (Dror, 1999); continuing into the $20^{\text {th }}$ century as animal science became more regulated (Lederer, 1992); and culminating in the standardization of laboratory animals from the late 1940s (Kirk, 2014). The UC-D experiments also informed subsequent research, giving rise to formal sets of guidelines about how to manage the affective qualities of laboratory dogs (Andersen, 1970) and continue to inform practice (e.g. Tomkins et al, 2011).

Figure 1. The outdoor kennel facilities of 'Project Six', University of California Davis. The key features of the colony are clearly discernible; each rectangular pen houses two beagles 
(visible in the nearest pen) and each pen corners onto three others, allowing 'muzzle contact' between 8 dogs. A covered walkway, allowing caretakers access to the pens, can also be seen. The pens themselves feature two half-barrels which provide shade, a lookout post, and a kennel. The floor of each pen is covered in crushed rock. In the background can be seen a 30 ft. tower designed to allow observation of the colony by a resident psychologist. Reprinted with permission from Defining the Laboratory Animal (1971: 265) by the National Academy of Sciences, Courtesy of the National Academies Press, Washington, D.C.

\section{References}

Acampora R (2006) Corporeal Compassion. Pittsburgh: University of Pittsburgh Press.

Andersen AC (1964) Air conditioned cages designed to minimize kennel problems. Laboratory Animal Care 14(4):292-303.

Andersen AC (1955) Debarking in a kennel: Technic and results. Veterinary Medicine 50(9):409-411.

Andersen AC (1970) The Beagle as an Experimental Dog. Ames, Iowa: The Iowa State University Press.

Andersen AC \& Goldman M (1960) An evaluation of an outdoor kennel for dogs. Journal of the American Veterinary Medical Association 137(2):129-135.

Andersen AC \& Hart G (1955) Kennel construction and management in relation to longevity studies in the dog. Journal of the American Veterinary Medical Association 126: 366373.

Appleton D \& Appleton C (1967) The production of the research beagle. Journal of the Institute of Animal Technicians 18(3): 124-130.

Barad K (2007) Meeting the Universe Halfway. Durham \& London: Duke University Press.

Berlant L (2011) Cruel Optimism. Durham \& London: Dukc University Press.

Burch GE (1959) Of the normal dog. The American Heart Journal 58(6): 805-806.

Candea M (2013) Habituating meerkats and redescribing animal behaviour science. Theory, Culture \& Society 30(7-8):105-128.

Dames \& Moore (1995) Final Community Relations Plan Laboratory for Energy-Related Health Research Environmental Restoration, Sacramento, California.

Davies G (2012) Caring for the multiple and the multitude: Assembling animal welfare and enabling ethical critique. Environment and Planning D: Society and Space 30(4):623638. 
Davies G (2013) Mobilizing experimental life: Spaces of becoming with mutant mice. Theory, Culture \& Society 30(7-8): 129-153.

Despret V (2013) Responding bodies and partial affinities in human-animal worlds. Theory, Culture \& Society 30(7-8): 51-76.

Despret V (2004) The body we care for: Figures of anthropo-zoo-genesis. Body \& Society, 10: $111-134$.

Dror O (1999) The affect of experiment: The turn to emotions in Anglo-American physiology, 1900-1940. Isis 90(2): 205-237.

Greenhough B (2010) A logic of care beyond health geography. Area 42(1): 136-138.

Greenhough B \& Roe E (2011) Ethics, space, and somatic sensibilities: Comparing relationships between scientific researchers and their human and animal experimental subjects. Environment and Planning D: Society and Space 29(1): 47-66.

Haraway D (1991) Simians, Cyborgs, and Women: The Reinvention of Nature. New York: Routledge.

Haraway D (1997)

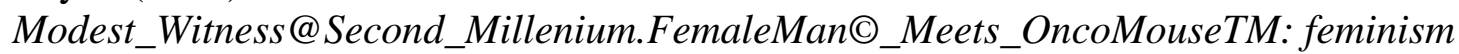
and technoscience. New York: Routledge.

Haraway D (2011) Species matters, human advocacy: In the promising grip of earthly oxymorons. In: DeKoven M \& Lundblad M (eds) Species Matters. New York: Columbia University Press.

Haraway D (2008) When Species Meet. Minneapolis: University of Minnesota Press.

Harbers H (2010) Animal farm love stories: About care and economy. In: Mol A Moser I \& Pols J (eds) Care in Practice: On Tinkering in Clinics, Homes and Farms. New Brunswick: Transaction Press.

Holmberg T (2008) A feeling for the animal: On becoming an experimentalist. Society \& Animals 16: 316-335.

Johnson, E (2015) Of lobsters, laboratories and war: Animal studies and the temporality of more-than-human encounters. Environment and Planning D: Society and Space. 33(2): 296-313.

Kirk R (2014) The invention of the "stressed animal" and the development of a science of animal welfare, 1947-86. In: Cantor D \& Ramsden E (eds) Stress, Shock, and Adaptation in the Twentieth Century. Rochester, NY: University of Rochester Press.

Latimer J (2013) Being alongside: Rethinking relations of different kinds. Theory, Culture \& Society 30(7-8): 77-104. 
Latimer J Miele M (2013) Naturecultures? Science, affect and the non-human. Theory, Culture \& Society 30(7-8): 5-31.

Latour B (1997) Stenger's shibboleth. In: Stengers I Power and Invention: Situating Science. Minneapolis: University of Minnesota Press.

Law J (2010) Care and killing: Tensions in veterinary practice. In: Mol A Moser I \& Pols J (eds) Care in Practice: On Tinkering in Clinics, Homes and Farms. New Brunswick: Transaction Press.

Lederer S (1992) Political animals: The shaping of biomedical research literature in Twentieth-Century America. Isis 83(1): 61-79.

Lee N (2008) Awake, asleep, adult, child: A a-humanist account of persons. Body \& Society 14: 57-74.

Manning E (2009) What if it didn't begin and end with containment? Towards a leaky sense of self. Body \& Society 15: 33-45.

McEwan C \& Goodman M (2010) Place, geography and the ethics of care. Ethics, Place and Environment 13: 103-112.

McKelvie D \& Solarz AK (1966) Personnel problems. Journal of the Institute of Animal Technicians 17(3): 109-115.

McKelvie DH et al (1971) The standardized dog as a laboratory animal. In: National Academy of Sciences (ed). Defining the Laboratory Animal. Washington, DC: National Academy of Sciences. 628.

McKelvie DH \& Andersen AC. (1966) Production and care of laboratory Beagles. Journal of the Institute of Animal Technicians 17(1):25-33.

Mol A (2008) The Logic of Care: Health and the Problem of Patient Choice. Abingdon, Oxon: Routledge.

Mol A Moser I \& PolsJ (2010) Care: Putting practice into theory. In: Mol A, Moser I \& Pols $\mathrm{J}$ (eds) Care in Practice: On Tinkering in Clinics, Homes and Farms. New Brunswick: Transaction Press.

Moser I (2010) Perhaps tears should not be counted but wiped away: On quality and improvement in dementia care. In: Mol A Moser I \& Pols J (eds) Care in Practice: On Tinkering in Clinics, Homes and Farms. New Brunswick: Transaction Press.

Paddock RC (1994) Fallout from toxic beagle experiments: Davis residents feel betrayed by how nuclear tests occurred at kennels. Los Angeles Times. A1.

Pickersgill M (2012) The co-production of science, ethics and emotion. Science, Technology \& Human Values 37(6): 579-603. 
Eva Giraud and Gregory Hollin

Puig de la Bellacasa M (2011) Matters of care in technoscience: Assembling neglected things. Social Studies of Science 41(1): 85-106.

Reinert H. \& Smith G (1963) The establishment of an experimental beagle colony. Journal of the Animal Technicians Association 14(2): 73-82.

Scott J (1970) A laboratory breed. Science November 723.

Shukin N (2009) Animal Capital. Minneapolis: University of Minnesota Press.

Silverman C (2012) Understanding Autism: Parents, Doctors, and the History of a Disorder. Princeton, New Jersey: Princeton University Press.

Singleton V (2010) Good farming: Control or care? In: Mol A Moser I \& Pols (eds) Care in Practice: On Tinkering in Clinics, Homes and Farms. New Brunswick: Transaction Press.

Solarz AK (1970) Behavior. In: Andersen AC (ed) The Beagle as an Experimental Dog. Ames, Iowa: The Iowa State University Press, 616.

Solarz AK (1965) Classification of emotional responses and their relation to dominancesubmission in adult beagle dyads. Psychological Reports 16: 1253-1258.

Solarz AK (1964) Effects of early adult x-irradiation upon emotional display in the aged female beagle: A negative finding. Psychological Reports 15(3): 927-930.

Stengers I (2010) Cosmopolitics I. Minneapolis: University of Minnesota Press.

Stengers I (2011) Cosmopolitics II. Minneapolis: University of Minnesota Press.

Stengers I (1997) Power and Invention: Situating Science. Minneapolis: University of Minnesota Press.

Stiegler B (2010) Taking Care of Youth and the Generations. Stanford: Stanford University Press.

Tomkins LM Thomson PC \& McGreevy PD (2011) Behavioral and physiological predictors of guide dog success. Journal of Veterinary Behavior: Clinical Applications and Research 6(3): 178-187.

Twine R (2010) Animals as Biotechnology. Oxford: Earthscan.

Wagner M (2011) In The Studio - Dr. Marvin Goldman - Radiation Laboratory. Available at: https://archive.org/details/inthestudio-drmarvingoldman-radiationbio.

Zinn RD (1968) The research dog. Journal of the American Veterinary Medical Association 153(12): 1883-6. 
Eva Giraud is a lecturer in Media, Communication and Culture at Keele University. Her work is concerned with facilitating dialogue between social movement studies - with a focus on criticalactivist perspectives, participatory methodologies and non-hierarchical communication practices and theoretical work exploring more-than-human relations. She is currently finishing a research monograph, which discusses these themes in relation to the practices of contemporary anticapitalist, animal and environmental activism. Correspondence address: Eva Giraud, Department of Media, Communication \& Culture, Keele University, UK, ST5 5BG. e.giraud@keele.ac.uk

Greg Hollin is a postdoctoral researcher at the Institute for Science and Society at The University of Nottingham. His research is primarily socio-historical and concerned with understandings of autism within the psychological and biological sciences. Correspondence address: Gregory Hollin, Institute for Science \& Society, Law \& Social Sciences Building, University of Nottingham, UK, NG7 2RD. gregory.hollin@nottingham.ac.uk 